an answer to the problems which face biologists; its potential service is to lead to a more precise formulation of them.

Mr. Sommerhoff has made a worth-while contribution towards clarity of thought in a field in which precision has often been sadly lacking, and his book will be of value to all who find themselves tempted to wonder what the conventional biological phrases really denote. It seems to me, however, that he may have over-estimated the applicability of his concept of directive correlation, at least in its simple form. Many instances of "biological purposiveness" seem to involve not so much an adaptation to an external state of affairs, but rather the alteration of the environment to fit in with an internally determined course of action. A bird not only builds a nest to suit the lie of the twigs, but chooses a part of the bush which suits the nest. The model of a crystal growing in an impure solution may be as relevant as that of a radar gunsight.

C. H. WADDINGTON

\section{BERKELEY'S SCIENTIFIC WORKS}

The Works of George Berkeley, Bishop of Cloyne Edited by A. A. Luce and T. E. Jessop. (Bibliotheca Britannica Philosophica.) Vol. 4: De Motu with an English translation, The Analyst, a Defence of Freethinking in Mathematics, Reasons for not replying to Mr. Walton's Full Ansuer, Arithmetica and Miscellanea Mathematica, Of Infinites, Letters on Vesuvius, on Petrifactions, and on Earthquakes, Description of the Cave of Dunmore. Edited by Dr. A. A. Luce. Pp. viii +264. (London and Edinburgh: Thomas Nelson and Sons, Ltd., 1951.) $30 s$. net.

7 HIS fourth volume of the new edition of Bishop

Berkeley's works collects together those writings which can be labelled as scientific. Of these, "The Analyst" would have been considered the most important in his own day; but "De Motu" has a certain topical interest for the twentieth century which it did not have for the eighteenth.

The Latin text of the second edition of "De Motu" is reproduced here, with a translation by the editor. 'This essay was written for a prize offered by the Paris Academy of Sciences in 1720, which it failed to win. It would appear to have been hurriedly composed, as the argument is not so well put as in Berkeley's other works, and it does not live up to its very general title. As the editor says, it should have been called "Motion without Matter". Berkeley is arguing that the science of mechanies can be developed in accordance with his own philosophical principles and that by so doing obscurities and inconsistencies, for example, the Newtonian notion of absolute space and motion, can be eliminated. $\mathrm{He}$ is expounding what would now be called a Positivist or Phenomenalist interpretation of science, much on the lines of Ernst Mach a century and a half later, to mention only one, perhaps the best, exponent. Of course, Berkeley, unlike later phenomenalists, does not resolve the whole universe into phenomena, but makes a reservation in favour of active minds or spirits.

"The Analyst", first published in 1734, was an important contribution to the long controversy over the use of infinitesimals in mathematics; a controversy of which the echoes still remain and which really began with the paradoxes of Zeno in the fifth century B.C. Berkeley's purpose in entering on the controversy is characteristic of him, and stated in the sub-title, "A Discourse Addressed to an Infidel Mathematician". The mathematician addressed was probably Edmund Halley, who is said to have declared the doctrines of Christianity to be incomprehensible. Berkeley retorted that the doctrines of the new analytical school of mathematics were far less comprehensible, indeed downright contradictory, whether in the form of Leibniz's differential calculus or Newton's fluxions. "It is curious to observe what subtilty and skill this great genius [Newton] employs to struggle with an insuperable difficulty; and through what labyrinths he endeavours to escape the doctrine of infinitesimals ; which as it intrudes upon him whether he will or no, so it is admitted and embraced by others without the least repugnance. Leibniz and his followers in their calculus differentialis making no manner of scruple, first to suppose, and secondly to reject, quantities infinitely small ; . . ." (p. 75). Berkeley concludes that the method works by reason of compensating errors, and "that, however useful it may be, it must be considered only as a presumption, as a knack, an art, rather an artifice, but not a scientific demonstration" (p. 81). This seems to have been Newton's own view when he wrote his "Principia", though Berkeley also attacks some of the statements made there (Book 2, Lemma 2).

The remaining writings in the volume contain Berkeley's replies to critics in the mathematical controversy-good hard hitting, but bringing out no new mathematical points-and some early papers. The one on "Infinites" shows Berkeley already con. cerned with mathematical problems in 1705-9. The letters on "Vesuvius", "Petrifactions" and "Earth quakes" and the "Description of the Cave of Dunmore" show the strong empirical interests of this idealist philosopher. The editing and printing of this volume maintain the standards of its predecessors ; higher praise is not necessary or possible.

A. D. RITChIF

\section{MARINE ANIMALS AND PLANTS}

Life of the Shore and Shallow Sea

By Dr. Douglas P. Wilson. Second edition, com. pletely revised and reset. Pp. xvii $+213+45$ plates. (London: Nicholson and Watson, Ltd., 1951.) 15s. net.

THE second edition of Dr. D. P. Wilson's popular book on marine animals and plants has been thoroughly revised and reset. The coloured frontispiece has been replaced by a black-and-white study of a John Dory poised over a gorgonid, and though the one hundred and twenty-eight photographs have been reduced to ninety-eight, many of these are new. Pictures are what one looks at first on opening such a book, and no praise can be high enough for the beauty, elarity and artistic merits of Dr. Wilson's photographs of living marine animals. The patience and skill that produced them are unequalled. Feather stars (Fig. 22), the beadlet anemone (Fig. 51), Physalia catching a fish (Fig. 61), larvæ from the plankton (Figs. 72-75) and sea horses (Fig. 91) are superb. Each photograph is accompanied by a magnification figure. If a suggestion can be made to so expert a photographer, it is that Fig. 31 of $A$ sterina gibbosa does not give a fair idea of this little starfish, 